\title{
Inhalt
}

Vorwort ...................... VII

Einleitung ..................... 1

Norbert Wiggershaus

Zur Frage der Planung für die verdeckte Aufstellung westdeutscher Verteidigungskräfte in Konrad Adenauers sicherheitspolitischer Konzeption 1950

I. Die außen- und sicherheitspolitische Konzeption im Zeichen des OstWest-Konflikts ...................

II. Die Entwicklung der sicherheitspolitischen Grundpositionen 1948/49 .

III. Die Sicherheitspolitik bis zum Ausbruch des Korea-Krieges:

Forderung nach einer Sicherheitsgarantie und Projektierung von Zwischenlösungen für einen offiziellen Verteidigungsbeitrag . . . . .

IV. Die Reaktion auf den Ausbruch des Korea-Krieges:

Das Angebot offener und verdeckter Aufrüstung im Sommer 1950 . .

V. Die erzwungene Aufgabe des Konzepts der Übergangslösung und der Beginn der Vorbereitung eines deutschen Kontingents im Rahmen einer übernationalen Streitmacht im Herbst 1950 . . . . . . . . . . .

\section{Heinz-Ludger Borgert}

Zur Entstehung, Entwicklung und Struktur der Dienstgruppen in der britischen und amerikanischen Besatzungszone Westdeutschlands 1945-1950 .

I. „Wiederbewaffnungsfrage ${ }^{\alpha}$ und politischer Entscheidungsprozeß . . 89

II. Die Entstehung der Dienstgruppen 1945-1947 . . . . . . . . . 92

1. Die „Operation Eclipse ${ }^{\alpha}$. . . . . . . . . . . . . . 92

2. Die Dienstgruppen in der britischen Besatzungszone . . . . . . 94

3. Die Dienstgruppen in der amerikanischen Besatzungszone . . . . 99

4. Der ${ }_{n}$ Deutsche Minenräumdienst ${ }^{\alpha}$. . . . . . . . . . . . 101

III. Die Wandlungen im internationalen Mächtesystem 1945-1949 . . . 106 
IV. Der Neuaufbau von Dienstgruppen in der britischen und amerikanischen Besatzungszone 1947-1950 . . . . . . . . . . . 109

1. Die "Organisation Gehlen" . . . . . . . . . . 109

2. Die "Operational History (German) Section" . . . . . . . 110

3. Die "Deutsche Zivile Arbeitsorganisation" . . . . . . . 112

4. Die "Dienstgruppen ${ }^{\star}$ unter amerikanischer Aufsicht . . . . . 115

a) Die "Industriepolizei" . . . . . . . . . . . 115

b) Die "Zivilen technischen Dienstgruppen" . . . . . . 116

V. Die „Dienstgruppen“ als westdeutscher Verteidigungsbeitrag . . . 122

1. Die Anerkennung der „Dienstgruppen“ als ein Beitrag zur militärischen Sicherung der Bundesrepublik Deutschland . . . . . .

2. Der Stellenwert der "Dienstgruppen " innerhalb der westdeutschen verteidigungspolitischen Überlegungen . . . . . . . .

\section{Walter Stürm}

Uberlegungen über die Verwendung der deutschen Dienstgruppen als Verteidigungsbeitrag seit $1950 \ldots \ldots \ldots$. . . . . . .

I. Uberlegungen zur Einbeziehung der Hilfsformationen der britischen und amerikanischen Besatzungstruppen in die Vorbereitungen eines deutschen Verteidigungsbeitrages nach der Korea-Krise . . . . . .

II. Deutsche Hilfsformationen bei der französischen Besatzungsmacht . . 158

III. Die Erörterung von Dienstgruppenfragen im Deutschen Bundestag 1950-1955

IV. Dienstgruppen während der EVG-Planung 1951-1954 . . . . . . 172

V. Dienstgruppen nach dem Scheitern der EVG 1954 . . . . . . . . 193

VI. Exkurs:

Besonderheiten bei der Entwicklung der Marine-Dienstgruppen . . . 202

vII. Schlußbetrachtung . . . . . . . . . . . . . . . 208

Anlage ..................... 210

Abkürzungen . . . . . . . . . . . . 215

Quellen und Literatur . . . . . . . . . . . . 217

Personenregister .................. . . 225 